Thorax, 1977, 32, 749-751

\title{
Incidence of decompression-induced pulmonary haemorrhage in young and old rats
}

\author{
H. S. FANG AND B. F. GUO \\ From the Department of Physiology, College of Medicine, National Taiwan University, Taipei, \\ Taiwan, China
}

Fang, H. S. and Guo, B. F. (1977). Thorax, 32, 749-751. Incidence of decompression-induced pulmonary haemorrhage in young and old rats. Seventeen young rats (40-52 days of age) and 17 old rats (545-702 days of age) were decompressed from one atmospheric pressure to an ambient pressure of $30 \mathrm{mmHg}$ in 0.25 second. It was found that 11 of 34 young lungs (32\%) and 23 of 34 old lungs $(68 \%)$ showed decompression-induced pulmonary haemorrhage. The difference was statistically significant. The pulmonary haemorrhage of the old rats was markedly more severe than that of the young rats.

It is generally accepted that the delicate structure of the pulmonary tissue is potentially the most vulnerable part of the body during a rapid decompression. In our previous studies evidence has been presented that the frequency of occurrence and the severity of decompression-induced pulmonary haemorrhage could be influenced by binding of the body (Fang, 1966), bilateral cervical vagotomy, occlusion of carotid arteries and intravenous administration of epinephrine (Fang and Tang, 1972), prolonged starvation (Fang and Lin, 1972) or semistarvation (Lin and Fang, 1973), hypothalamic obesity (Liu and Fang, 1975), long-term intermittent exposure to hypoxia (Fang and Chen, 1976a), and previous repeated decompressions (Fang and Chen, 1976b). So far as we are aware, no study has ever been reported concerning the influence of age on the incidence of decompressioninduced pulmonary haemorrhage. The present work was done for this purpose.

\section{Methods}

Seventeen young rats (40-52 days of age) and 17 old rats (545-702 days of age) were used for these experiments. All rats (Sprague Dawley strain) were unanaesthetised. Rapid decompression was accomplished by the rupture of a sheet of exposed x-ray film separating a small animal chamber at one atmospheric pressure and a large vacuum chamber, using the method described previously (Fang, 1966). The small animal chamber was kept open to room air until immediately before the rapid decompression. The decompression rate was measured by means of a Statham model PM6 \pm 15-350 pressure transducer through a Grass polygraph. The time needed for rapid decompression from $760 \mathrm{mmHg}$ to $30 \mathrm{mmHg}$, corresponding to a simulated altitude from ground level to 72000 feet, was 0.25 second. In each experiment, a pair of rats, one young and one old, were decompressed together. In order to avoid post-decompression hypoxia acting as a complicating factor, all rats were recompressed after decompression. The rats were killed and necropsy was carried out within a few minutes after recompression. The lungs were then carefully examined for gross evidence of haemorrhage. The severity of decompressioninduced pulmonary haemorrhage was graded according to the following scale: 0 no haemorrhage; + slight haemorrhage (a few petechial haemorrhages); ++ moderate haemorrhage (haemorrhagic area was less than $25 \%$ of the lungs); and +++ severe haemorrhage (haemorrhagic area was $25-50 \%$ of the lungs).

\section{Results}

The frequency of occurrence and the severity of pulmonary haemorrhage in both young and old rats subjected to a single rapid decompression are indicated in the Table. It will be noted that only 11 of 34 young lungs $(32 \%)$ revealed lung damage varying from slight to moderate haemorrhage. No severe pulmonary haemorrhage was found in such young rats. In the old rats, however, lung damage 
Table Pulmonary haemorrhage in young and old rats after a single rapid decompression from one atmospheric pressure to an ambient pressure of $30 \mathrm{~mm} \mathrm{Hg}$ in 0.25 second

\begin{tabular}{|c|c|c|c|c|c|c|c|c|c|c|c|}
\hline \multicolumn{6}{|c|}{ Young rats } & \multicolumn{6}{|l|}{ Old rats } \\
\hline \multirow[b]{2}{*}{ Rat no. } & \multirow[b]{2}{*}{$\operatorname{Sex}$} & \multirow[b]{2}{*}{$\begin{array}{l}\text { Age } \\
\text { (days) }\end{array}$} & \multirow{2}{*}{$\begin{array}{l}\text { Body } \\
\text { weight } \\
(g)\end{array}$} & \multicolumn{2}{|c|}{$\begin{array}{l}\text { Pulmonary } \\
\text { haemorrhage* }\end{array}$} & \multirow[b]{2}{*}{ Rat no. } & \multirow[b]{2}{*}{ Sex } & \multirow[b]{2}{*}{$\begin{array}{l}\text { Age } \\
\text { (days) }\end{array}$} & \multirow{2}{*}{$\begin{array}{l}\text { Body } \\
\text { weight } \\
(g)\end{array}$} & \multicolumn{2}{|c|}{$\begin{array}{l}\text { Pulmonary } \\
\text { haemorrhage* }\end{array}$} \\
\hline & & & & $\begin{array}{l}R t \\
\text { lung }\end{array}$ & $\begin{array}{l}\text { Lt } \\
\text { lung }\end{array}$ & & & & & $\begin{array}{l}\text { Rt } \\
\text { lung }\end{array}$ & $\begin{array}{l}\text { Lt } \\
\text { lung }\end{array}$ \\
\hline 1 & $\mathbf{M}$ & 51 & 76 & 0 & 0 & 2 & $\mathbf{M}$ & 605 & 433 & $++t$ & $+t$ \\
\hline 3 & $\mathbf{M}$ & 51 & 79 & 0 & 0 & 4 & $\mathbf{M}$ & 605 & 431 & + & + \\
\hline 5 & $\mathbf{M}$ & 40 & 70 & + & + & 6 & $\mathbf{M}$ & 605 & 434 & $+t+$ & $+t+$ \\
\hline 7 & $\mathbf{M}$ & 40 & 66 & 0 & + & 8 & $\mathbf{M}$ & 605 & 399 & + & 0 \\
\hline 9 & $\mathrm{~F}$ & 51 & 67 & 0 & 0 & 10 & $\mathrm{~F}$ & 545 & 282 & + & 0 \\
\hline 11 & $\mathrm{~F}$ & 51 & 46 & 0 & 0 & 12 & $\mathbf{F}$ & 545 & 264 & 0 & 0 \\
\hline 13 & $\mathrm{~F}$ & 51 & 67 & 0 & 0 & 14 & $\mathbf{F}$ & 545 & 298 & $+t+$ & $+t+$ \\
\hline 15 & $\mathbf{F}$ & 51 & 75 & 0 & 0 & 16 & $\mathbf{F}$ & 605 & 236 & ++ & ++ \\
\hline 17 & $\mathbf{F}$ & 52 & 72 & + & $+t$ & 18 & $\mathbf{F}$ & 557 & 300 & ++ & ++ \\
\hline 19 & $\mathbf{M}$ & 52 & 118 & + & 0 & 20 & $\mathbf{F}$ & 557 & 286 & $+t+$ & $+t$ \\
\hline 21 & $\mathbf{M}$ & 52 & 115 & 0 & 0 & 22 & $\mathbf{M}$ & 702 & 452 & + & ++ \\
\hline 23 & $\mathbf{M}$ & 50 & 72 & + & + & 24 & $\mathbf{M}$ & 702 & 435 & 0 & 0 \\
\hline 25 & $\mathbf{F}$ & 51 & 79 & 0 & 0 & 26 & $\mathrm{~F}$ & 702 & 240 & + & 0 \\
\hline 27 & $\mathrm{~F}$ & 51 & 44 & 0 & 0 & 28 & $\mathrm{~F}$ & 702 & 229 & 0 & 0 \\
\hline 29 & $\mathbf{M}$ & 50 & 79 & + & + & 30 & $\mathbf{M}$ & 702 & 455 & $+t+$ & $+t+$ \\
\hline 31 & $\mathbf{M}$ & 50 & 93 & 0 & 0 & 32 & $\mathbf{M}$ & 702 & 415 & 0 & + \\
\hline 33 & $\mathbf{M}$ & 50 & 71 & + & 0 & 34 & $\mathbf{M}$ & 646 & 415 & 0 & + \\
\hline \multicolumn{2}{|c|}{ Average } & 50 & 77 & & & & & 625 & 353 & & \\
\hline \multicolumn{4}{|c|}{ Total lungs showing haemorrhage } & \multicolumn{2}{|c|}{$11 \dagger$} & \multicolumn{4}{|c|}{ Total lungs showing haemorrhage } & \multicolumn{2}{|l|}{$23 \dagger$} \\
\hline
\end{tabular}

*0 No haemorrhage. + Slight haemorrhage. ++ Moderate haemorrhage. +++ Severe haemorrhage.

$\dagger \mathbf{P}<0.01$.

varying from mild to severe haemorrhage was observed in 23 of 34 lungs $(68 \%)$. The difference was statistically significant $\left(P<0.01, \chi^{2}\right.$ test $)$.

\section{Discussion}

The two lungs of experimental animals are essentially two extensible sacs filled with air. When the ambient pressure decreases, the volume of air in the lungs must increase, the excess escaping through the airways to allow the alveolar volume to remain approximately unchanged. When the ambient pressure decreases at a rate greater than that by which air can escape through the airways, rapid expansion of the lungs may overstretch the alveolar walls to the point of rupture. In addition, it is also possible that this sudden rise of intrapulmonary pressure may produce a bruising effect by pushing the inflated lungs against the rigid thoracic wall (Whitehorn et al., 1947). Pulmonary haemorrhage may thus result. The frequency and severity of such pulmonary haemorrhages depend on several factors. The most important of these are $(a)$ the total reduction in pressure, $(b)$ the rate of decompression of the chamber, $(c)$ the volume of air contained in the lungs, and $(d)$ the rate of decompression of the lungs.

In the present study, both young and old rats were subjected to the same pressure differential and the same decompression rate of the animal chamber. It is, therefore, not necessary to take these two factors into special consideration. The 2 rate of decompression of the lungs may be influ- $\overrightarrow{\vec{O}}$ enced by the volume of lung air to be expelled and 3 the flow resistance offered by the pulmonary airways. It has been shown that old subjects usually? reveal an increased functional residual capacity (Greifenstein et al., 1952; Bouhuys, 1963) and a음 high resistance to air flow in the lungs (Frank et $\times$ al., 1957; Cohn and Donoso, 1963). If there is a real increase in functional residual capacity together with a significant increase in flow resistance of pulmonary airways in old rats, it would be reasonable to expect a high incidence of $\frac{}{\triangle}$ decompression-induced lung damage. In addition, $D$ it is possible that the less distensible vascular tree?. in old lungs may also facilitate pulmonary ज haemorrhage after rapid decompression.

In our study it appears that the lungs of 557-and 605-day-old rats tolerated decompression less wellew than those of the other old rats. It is possible that this could have been related to a particular suse ceptibility of these litters, though the numbers are too small to be sure of this. Another factor which ${ }^{\text {? }}$ may play a part in provoking pulmonary haemor- $-\frac{T}{2}$ rhage is the phase in the respiratory cycle in which decompression occurs, the damage being likely to? be greatest at full inspiration. As this was not con $\frac{\mathbb{D}}{\Omega}$ trolled in our experiments it may account for someo of the observed differences. 
This investigation was supported by a research grant from the National Science Council of the Republic of China.

\section{References}

Bouhuys, A. (1963). Pulmonary nitrogen clearance in relation to age in healthy males. Journal of Applied Physiology, 18, 297-300.

Cohn, J. E., and Donoso, H. D. (1963). Mechanical properties of lung in normal men over 60 years old. Journal of Clinical Investigation, 42, 1406-1410.

Fang, H. S. (1966). Pulmonary hemorrhage of the toad produced by explosive decompression to an ambient pressure of $30 \mathrm{mmHg}$. Aerospace Medicine, 37, 949 950.

Fang, H. S., and Chen, C. F. (1976a). Influence of long-term intermittent exposures to hypoxia on decompression-induced pulmonary haemorrhage. Thorax, 31, 91-93.

Fang, H. S., and Chen, C. F. (1976b). Tolerance to explosive decompression following repeated decompressions for a total of 20 exposures. Proceedings of the National Science Council, Republic of China, No. 9, Part 2, 335-340.

Fang, H. S., and Lin, H. S. (1972). The influence of prolonged starvation on the frequency of occurrence of decompression-induced pulmonary hemorrhage. Aerospace Medicine, 43, 606-609.
Fang, H. S., and Tang, C. M. (1972). Effects of vagotomy and increased blood pressure on the incidence of decompression-induced pulmonary hemorrhage. Space Life Sciences, 3, 268-270.

Frank, N. R., Mead, J., and Ferris, B. G., Jr. (1957). The mechanical behavior of the lungs in healthy elderly persons. Journal of Clinical Investigation, 36, 1680-1687.

Greifenstein, F. E., King, R. M., Latch, S. S., and Comroe, J. H., Jr. (1952). Pulmonary function studies in healthy men and women 50 years and older. Journal of Applied Physiology, 4, 641-648.

Lin, J. D., and Fang, H. S. (1973). The influence of prolonged semi-starvation on the incidence of pulmonary hemorrhage following rapid decompression. Space Life Sciences, 4, 338-340.

Liu, H. J., and Fang, H. S. (1975). Influence of hypothalamic hyperphagia on tolerance of lung to explosive decompression. Aviation, Space, and Environmental Medicine, 46, 823-825.

Whitehorn, W. V., Lein, A., and Hitchcock, F. A. (1947). The effect of binding of the abdomen and thorax on pulmonary lesions produced by explosive decompression. Journal of Aviation Medicine, 18, 102-104.

Requests for reprints to: Dr. H. S. Fang, Department of Physiology, National Taiwan University College of Medicine, No. 1 Jen Ai Road, 1st Section, Taipei, Taiwan 100, Republic of China. 